\title{
Withdrawing to a Virtual World: Associations Between Subtypes of Withdrawal, Media Use, and Maladjustment in Emerging Adults
}

\author{
Larry J. Nelson \\ Brigham Young University - Provo \\ Sarah M. Coyne \\ Brigham Young University - Provo, smcoyne@byu.edu \\ Emily Howard \\ Brigham Young University - Provo \\ Brandon N. Clifford \\ Brigham Young University - Provo \\ Follow this and additional works at: https://scholarsarchive.byu.edu/facpub \\ Part of the Other Social and Behavioral Sciences Commons
}

\section{Original Publication Citation}

Nelson, L. J., Coyne, S. M., *Howard, E*, \& Clifford, B. N. (2016). Withdrawing to a virtual world: Associations between subtypes of withdrawal, media use, and maladjustment in emerging adults. Developmental Psychology, 52, 933-942.

\section{BYU ScholarsArchive Citation}

Nelson, Larry J.; Coyne, Sarah M.; Howard, Emily; and Clifford, Brandon N., "Withdrawing to a Virtual World: Associations Between Subtypes of Withdrawal, Media Use, and Maladjustment in Emerging Adults" (2016). Faculty Publications. 4024.

https://scholarsarchive.byu.edu/facpub/4024

This Peer-Reviewed Article is brought to you for free and open access by BYU ScholarsArchive. It has been accepted for inclusion in Faculty Publications by an authorized administrator of BYU ScholarsArchive. For more information, please contact ellen_amatangelo@byu.edu. 


\title{
Withdrawing to a Virtual World: Associations Between Subtypes of Withdrawal, Media Use, and Maladjustment in Emerging Adults
}

\author{
Larry J. Nelson, Sarah M. Coyne, Emily Howard, and Brandon N. Clifford \\ Brigham Young University
}

\begin{abstract}
An approach-avoidance model of social withdrawal (Asendorpf, 1990) identifies 3 types of social withdrawal including shyness, unsociability, and avoidance. Each appears to be uniquely associated with varying indicators of maladjustment in emerging adulthood (Nelson, 2013) but little, if any, work has been done to see how they might be linked to media use in the third decade of life. Therefore, the purpose of this study was to examine longitudinally the links between subtypes of social withdrawal, connective media (e.g., e-mail, social networking) and problematic (forms of media such as violent video games that, when used in high amounts, have been found to be linked to indices of maladjustment) media use, and internalizing and externalizing behaviors. The participants in the study $\left(M_{\text {age }}=20.70, S D=1.98\right.$, range $=18-29$ at Time 2) consisted of 204 undergraduate students (58\% female) recruited from 2 large public universities in the United States who completed questionnaires at 2 points of time separated by 1 year. Results revealed that avoidant individuals use problematic forms of media more than average, unsociable, and shy individuals. Furthermore, problematic media use predicted more withdrawn behavior at Time 2 and mediated the relation between avoidance and externalizing behaviors over time. Few problems were found for unsociable behavior. The need to differentiate between multiple forms of withdrawal in emerging adulthood and their links with problematic forms of media and subsequent risk factors is discussed.
\end{abstract}

Keywords: social withdrawal, shyness, unsocial, avoidant, media

Research has revealed that shyness is a risk factor for maladjustment during emerging adulthood (see Bowker, Nelson, Markovic, \& Luster, 2014, for a recent review) but recent work has shown that shyness is just one form of social withdrawal with each subtype of withdrawal linked to different indices of adjustment and maladjustment during the third decade of life (Nelson, 2013). However, there is little if any longitudinal work examining factors that might affect the stability of withdrawn behaviors or the link between withdrawn behaviors and indices of adjustment or maladjustment over time. A popular stereotype exists that shy individuals cut themselves off from their social world by secluding themselves in their rooms/apartments and surrounding themselves with media rather than people. However, no empirical work with emerging adults has examined how subtypes of social withdrawal might be related to various forms of media use and how that media use might be related to the stability of withdrawal and its associations with indices of adjustment or maladjustment over time. Therefore, the purpose of this study was to conduct a short-term

This article was published Online First May 5, 2016.

Larry J. Nelson, Sarah M. Coyne, Emily Howard, and Brandon N. Clifford, School of Family Life, Brigham Young University.

We thank all of our colleagues associated with Project READY, and to the instructors and students at all Project READY data collection sites for their assistance. We also are grateful for the grant support of the Family Studies Center at Brigham Young University.

Correspondence concerning this article should be addressed to Larry J. Nelson, School of Family Life, Brigham Young University, 2091 JFSB, Provo, UT 84602. E-mail: larry_nelson@byu.edu longitudinal study examining the role of problematic media (forms of media such as violent video games that when used in high amounts have been found to be linked to indices of maladjustment) and connective media (e.g., e-mail, social networking) use in the stability of subtypes of social withdrawal and their links with internalizing problems (e.g., depression) and externalizing (e.g., use of illegal drugs, shoplifting or vandalizing, and smoking cigarettes) behaviors during emerging adulthood.

\section{Withdrawal in Emerging Adulthood}

The third decade of life is one during which instability is common, identity exploration is encouraged, expectations for selfreliance increase, and transitions into new social roles take place (Arnett, 2000). Much of this instability, exploration, and transition takes place in social settings (i.e., exploring one's identity by trying out different jobs, pursuing an education, and engaging in romantic relationships) so many of these features of emerging adulthood may be particularly challenging for individuals who are either afraid to or simply prefer not to interact socially. This underscores the need to better understand factors that are associated with adjustment or maladjustment for withdrawn individuals during emerging adulthood because rather than embrace these newfound opportunities for independence and engage in the social activities that would benefit their development (e.g., educational and vocational pursuits), some individuals might choose to withdraw from their social worlds. Indeed, as noted previously, there is a popular stereotype that shy individuals withdraw into virtual worlds that may limit or completely severe social interactions with others. However, there are few empirical inquiries into the topic so 
there is a need to examine the role that media use may play for withdrawn individuals.

\section{Withdrawal and Media Use}

There are competing views regarding the role that media may play in the lives of socially withdrawn individuals. According to the social compensation theory, media may be particularly beneficial for withdrawn individuals who may feel anxiety at interacting with others in a face-to-face setting (Sheldon, 2008). For example, it has been argued that shy individuals who used media to connect to online relationships may feel enabled and gain confidence which subsequently transfers to their offline relationships (e.g., Roberts, Smith, \& Pollock, 2000). Indeed, some feel that aspects of certain forms of media simply provide more opportunities to develop social skills (e.g., Birnie \& Horvath, 2002). Accordingly, this theory would suggest that media might "compensate" withdrawn individuals, and may even reduce withdrawn behaviors over time. Evidence to support this notion can be found in work showing that children who had low amounts of shyness online and high amounts of shyness offline benefitted from their interactions online as shown by a decrease in offline shyness over time (Roberts et al., 2000).

Conversely, the rich-get-richer hypothesis suggests that withdrawn individuals do not particularly benefit from media use (Kraut et al., 2002; Sheldon, 2008) by arguing that media use benefits individuals who already have strong social skills and are confident in their interactions with others. Socially "rich" individuals may use media as a way to reinforce their existing social skills and augment their already large friendship groups. For the socially "poor," online interactions cannot fully replicate face-to-face interactions causing media use by withdrawn individuals to be detrimental because the time that could be used to interact with others face-to-face is replaced or greatly reduced by the time spent using media which robs individuals of opportunities to develop greater levels of social competence (Henderson \& Zimbardo, 1998). As a result, socially withdrawn individuals may be at risk for other negative outcomes. For example, shy individuals who are addicted to using the Internet (Chak \& Leung, 2004; Yang \& Tung, 2007) and instant messaging (Huang \& Leung, 2009) tend to experience withdrawal, depression, and lower academic performance. In sum, there are both conceptual and empirical reasons to believe that media use by emerging adults has the potential to both positively and negatively impact withdrawn individuals but given the limited scope of this work there are a number of issues that need further attention to better understand the links between social withdrawal, media use, and developmental outcomes in emerging adulthood.

\section{Current Study}

Although there is a growing body of work devoted to explicating the role of media use in the lives of withdrawn individuals, there are several limitations to what has been done that point to areas that need further work. First, the majority of the existing work has examined shyness as a global construct rather than examining multiple forms of withdrawal. The term social withdrawal is considered an "umbrella construct" capturing internal motivations for removing oneself from social interaction (Coplan
\& Rubin, 2010). Approach-avoidance models of social withdrawal (e.g., Asendorpf, 1990) are useful in understanding the various reasons why individuals may withdraw from social settings. Specifically, shy individuals want to interact (high approach motive) but simultaneously experience wariness, fear, and anxiety (high avoidance motive). Others, referred to as unsociable, are believed to withdraw due to a low approach (but also low avoidance) tendency. In other words, they are not afraid of interacting and do not actively avoid others per se, but are simply less interested in initiating interactions with peers. Finally, some individuals actively avoid social interactions due to high avoidance and low approach motivations.

Recent work in emerging adulthood suggests that both shy and avoidant individuals (both men and women) experience more problems of an internalizing nature in their relationships (although the extent of the problems appear to be worse for avoidant individuals) whereas far fewer problems appear to exist for unsociable individuals (Nelson, 2013). These findings demonstrate the need to avoid global definitions of "shyness" and, instead, focus on multiple motivations that individuals have for withdrawing from social interactions. Thus, there is a need to examine how the three forms of withdrawal might be linked to media use, and how media use might mediate the stability of each form of withdrawal over time during the third decade of life.

The second problem with the existing work examining withdrawal and media use is the lack of specificity regarding the types of media use and the breadth of "outcome" variables examined. In the existing literature there are a number of discrepant findings and competing beliefs about the potentially beneficial versus harmful effects of media use for withdrawn individuals which may be due to the narrow focus on fairly positive aspects of media. For example, studies have examined social networking sites (Baker \& Oswald, 2010; Chan, 2011), instant messaging (e.g., Huang \& Leung, 2009) and general Internet use (Chak \& Leung, 2004; Yang $\&$ Tung, 2007). Several of these forms of media have an aspect about them related to connecting with others (e.g., social networking sites, messaging). However, it may be that in their desire to avoid social interaction as much as possible, individuals who engage in some withdrawn behaviors (i.e., avoidance) may be using forms of media that have little to do with connecting to others. Furthermore, some withdrawn individuals may not only choose to participate in forms of media that have very few social components to them but they may choose to use media that has been found to be linked to multiple forms of maladjustment to such an extent that they might be deemed harmful, or problematic.

Indeed, in terms of use, media can range from normative to pathological (Gentile, Coyne, \& Bricolo, 2013). We do not measure pathological use (or addiction to media) in the current study; instead we examine several types of media that may be labeled problematic (Rosser, Noor, \& Iantaffi, 2014). This line of reasoning may be analogous to other behaviors that are termed "problematic" in the literature, including problematic sexual behavior (Samenow, 2013) and substance use (Halley Grigsby, Forster, Soto, Baezconde-Garbanati, \& Unger, 2014). Again, both range from normative to pathological, with "problematic" levels being somewhere in between. For example, sexual activity itself is not problematic but when it occurs with numerous partners it has been found to be problematic (i.e., linked to a number of negative outcomes; e.g., Caspi et al., 1997). Similarly, there are many 
different types of media, some more problematic than others both in their content and the time spent engaged in them. For example, hours spent playing video games (particularly violent ones), online gambling, and pornography have all been linked to negative outcomes, including increased aggression (e.g., Anderson, Gentile, \& Buckley, 2007), addiction to media (e.g., Schmitt \& Livingston, 2015; Southern \& Hilton, 2015), and decreased empathy and pro-social behavior (Anderson et al., 2010; Linz, Donnerstein, \& Penrod, 1988; Padilla-Walker, Nelson, Carroll, \& Jensen, 2010). A media diet that includes a pattern of high levels of these types of media may be indicative of an overall problem with media that may be linked to negative outcomes for emerging adults. In sum, it is important to build on past work by distinguishing between positive (i.e., connective) and problematic forms of media use.

It is also important to address limitations in past work by broadening the possible correlates and outcomes of withdrawn individuals' engagement with media. There is a rather extensive body of work showing links between multiple forms of withdrawal and internalizing problems (e.g., depression, low self-esteem, and loneliness; see Coplan \& Rubin, 2010). There are fewer outcomes indicative of externalizing behavior commonly associated with withdrawn behaviors. However, externalizing problems are frequently found to be linked to problematic forms of media (e.g., violent video games; Padilla-Walker et al., 2010). Thus, to better understand the role of media use (both connective and problematic) there is a need to examine indices of both internalizing and externalizing problems. In sum, there is a need to examine both connective and problematic forms of media and a variety of outcomes including indices of both internalizing (e.g., depression) and externalizing (e.g., use of illegal drugs, shoplifting or vandalizing, and smoking cigarettes) problems.

The third limitation to the extant work is that most of it has focused on childhood and adolescence. Emerging adulthood is a time in which young people both expect and are granted greater levels of autonomy (e.g., Arnett, 2000; Aquilino, 2006; Wartman \& Savage, 2008). With this increased level of autonomy (and lower levels of parental monitoring for many who live outside the home), individuals have greater freedom to engage in the behaviors they want (e.g., use of media) including when they want and for how long they want. Withdrawn individuals are not forced into more social settings (e.g., classroom peer group) like in earlier ages. Instead, they may choose to withdraw into solitary settings to engage in solitary activities of their choosing. This is why the degree to which individuals do or do not want to interact (i.e., approach/avoidance motivations) may matter in what emerging adults choose to do in regard to media. Furthermore, there is a need to examine whether or not participation in these behaviors (e.g., media use) is related to the stability of the different forms of withdrawal. No study that we are aware of has longitudinally examined the stability of these forms of withdrawal during emerging adulthood, nor have they examined factors (e.g., media use) that contribute to the stability or instability of the nonsocial behaviors.

Taken together, there is a need to examine the links between multiple forms of withdrawal and multiple aspects of media use in emerging adulthood. Specifically, this study examined in emerging adulthood (a) the differences (examined via a person-centered approach) in the extent to which shy, unsociable, and avoidant individuals use multiple forms of media (i.e., e-mail, playing video games, playing violent video games, using social networking sites, gambling, and viewing pornography); (b) the role of media (employing continuous variables) in the stability of each subtype of withdrawal over time; and (c) the roles of both positive (i.e., connective) and problematic forms of media in the link between subtypes of social withdrawal and internalizing (e.g., depression) and externalizing (e.g., use of illegal drugs, shoplifting or vandalizing, smoking cigarettes) problems over time. Because this is some of the first work of its kind in emerging adulthood, there is little work upon which to build hypotheses. However, conceptually, we expected that unsociable behavior (because there is no real drive to avoid social interactions) and shy behavior (because the avoidance tendency is coupled with the approach tendency, or in other words an equally strong desire to interact with others) would be positively linked to more social, or connective, forms of media use and fewer forms of problematic media. Due to the strong drive to avoid social interactions, and based on work showing a link between avoidance and indices of maladjustment, it was expected that avoidant behavior would be linked to greater use of more problematic forms of media. Furthermore, it was expected that more frequent use of problematic media (i.e., media that is less connective and which has been linked to multiple maladaptive outcomes) at Time 1 would lead to increases in each form of withdrawal, respectively, at Time 2. Finally, it was expected that greater use of problematic media use at Time 1 would be linked to higher levels of depression and greater engagement in externalizing behaviors at Time 2 .

\section{Method}

Participants for this study were drawn from a study of emerging adults entitled ProjectREADY (Research Emerging Adults' Developmental Years). Time 1 data were collected during 20092010 and approximately 1 year later for Time 2 data. The sample for the current study $\left(M_{\text {age }}=20.70, S D=1.98\right.$, range $=18-29$ at Time 2) consisted of 355 undergraduate students (58\% female), 204 of which had complete data at Time 2 (58\% participation rate). A comparison of those who did and did not participate at Time 2 revealed that there were no significant differences on any of the Time 1 variables except for one (those who did not participate at Time $2[M=3.99]$ scored significantly higher on externalizing behaviors than those who did $[M=3.55])$. Participants were recruited from two large public universities in the United States (one located in the western United States and the other in the Midwest), and response rate varied by site, with an overall response rate of approximately $60 \%$ at Time 1 .

In terms of year in school (at Time 2), $42 \%$ of emerging adults were in their second year, $27 \%$ third year, $17 \%$ fourth year, and 5\% in their fifth year of college. Approximately $3 \%$ were enrolled in graduate school, and 5\% were not enrolled in college or graduate school. Eighty-five percent of emerging adults reported living outside of their parents' home in an apartment, house, or dormitory. Thirty-three percent reported that their parents' combined income was $\$ 50,000$ per year or less, and $28 \%$ reported combined parental income over $\$ 100,000$. Fifty percent of the sample described themselves as European American, while 32\% described themselves as Asian $(n=66), 5 \%$ described themselves as Hispanic/Latino, 2\% described themselves as African American, and 
$10 \%$ described themselves as biracial or having an ethnicity not listed.

\section{Procedure}

Participants completed the questionnaire via the Internet. The use of an online data collection protocol facilitated unified data collection across multiple university sites. At Time 1 participants were recruited through faculty's announcement of the study in undergraduate courses. Undergraduate courses were primarily introduction to psychology courses or large general education courses of the like in an attempt to access a broad range of students. Professors at the various universities were provided with a handout to give to their students that had a brief explanation of the study and directions for accessing the online survey. Interested students then accessed the survey with a class-specific recruitment code. Informed consent was obtained online, and each participant was given a survey that took approximately $45 \mathrm{~min}$ to complete. Participants were given a $\$ 20$ Amazon gift code for their participation. At Time 2, participants were contacted via e-mail and given a link to the same survey questions administered at Time 1. Participants were given a $\$ 50$ Amazon gift code for their participation at Time 2.

Subtypes of social withdrawal. Subtypes of social withdrawal were measured with the Child Social Preference Scale (Coplan, Prakash, O'Neil, \& Armer, 2004) that has been revised and adapted for college students (Nelson, 2013). Questions were answered on a 5-point scale ranging from 1 (strongly disagree) to 5 (strongly agree). Shyness was assessed using seven items (e.g., "I'd like to hang out with other people, but I'm sometimes nervous to"). Cronbach's alpha was acceptable at both time points: Time 1, $\alpha=.90$; Time $2, \alpha=.91$. Unsociable behavior was assessed using four items (e.g., "I'm just as happy to be by myself as with other people"). Cronbach's alpha for this scale was only moderate, likely because of the smaller number of items on this scale, Time $1, \alpha=$ .60 , Time $2, \alpha=.67$. Accordingly, this scale should be viewed with some caution. Avoidance was measured using six items (e.g., "I like to be with people," reverse coded).Cronbach's alpha was acceptable at both time points: Time $1, \alpha=.84$; Time $2, \alpha=.77$.

Two different analytical approaches were employed to address the specific research questions. For some of the analyses, we treated these subtypes of withdrawal as continuous variables. However, for other research questions, we employed a personcentered approach that has commonly been employed when studying these subtypes of withdrawal at various developmental stages (Coplan \& Weeks, 2010; Coplan et al., 2013; Nelson, 2013). Specifically, to examine differences between each form of withdrawal as well as nonwithdrawn individuals, groups were formed according to the following criteria. Those individuals who scored in the top quartile for shyness and in the bottom three quartiles for avoidance and unsociability formed the shy group (18\% of the sample). Those who scored in the top quartile for avoidance and the bottom three quartiles for shyness and unsociability formed the avoidant group ( $6 \%$ of the sample). Those who scored in the top quartile for unsociability and the bottom three quartiles for shyness and avoidance formed the unsociable group ( $8 \%$ of the sample). Finally, those who fell in the bottom three quartiles for all forms of withdrawal comprised the nonwithdrawn control group (44\% of the sample). A portion of the sample (24\%) did not fit into any of the groups because participants fell in the top quartile of two or more groups.

Media use. Participants were asked to estimate the number of hours they spent in an average week using different types of media, including e-mail, playing video games, playing violent video games, using social networking sites, gambling (online or offline), and viewing pornography. Weekly hourly estimates of media use have been used in a number of recent studies either on adolescence or emerging adults (Fraser, Padilla-Walker, Coyne, Nelson, \& Stockdale, 2012; Kaiser Family Foundation, 2010). It should also be noted that we did not specifically define violent video games for participants; rather, participants simply rated the number of hours they played such games. However, other research has found that self-reports of the levels of violence in video games tends to be highly correlated with expert ratings of violence in the same games, lending validity to this particular measure (e.g., Anderson et al., 2007; Gentile et al., 2009).

Conceptually, these items fall into two different subgroups, those that facilitate connection (e-mail and social networking) and those that are generally done in isolation and may be viewed as more problematic (playing video games, playing violent video games, pornography, gambling) based on their associations with indices of maladjustment as discussed previously. We group these accordingly in later analyses. Also, several media types were skewed (e.g., viewing pornography). A number of transformations were conducted with little improvement in the distribution of the scores; accordingly, this variable should be viewed with some caution.

Externalizing behaviors. Externalizing behaviors were measured using 10 items that asked participants to estimate how frequently they engaged in a number of externalizing behaviors (e.g., "use illegal drugs," "smoke cigarettes," "shoplift or vandalize"). Some of these items were adapted from Add Health and others written specifically for this study by our research team. Participants responded to items on a 6-point Likert scale ranging from 0 (none) to 5 (every day or almost every day). Cronbach's alpha was moderate at both time points: Time $1, \alpha=.66$, Time 2 , $\alpha=.61$.

Depression. Participants answered 8 questions from the original Center for Epidemiological Studies Depression scale (Radloff, 1977) to assess depression levels. Questions were answered on a 3 -point scale ranging from 1 (never) to 3 (most of the time). Sample questions include, "I felt everything I did was an effort," and "I felt sad." Cronbach's alpha was acceptable at both time points: Time $1, \alpha=.79$, Time $2, \alpha=.81$.

\section{Results}

\section{Group Differences by Withdrawal Type}

The first analyses were conducted to examine differences in media use for different types of withdrawn individuals (at Time 1). See Table 1 for means and standard deviations. A multivariate analysis of variance revealed that media use differed by withdrawn subtype, $F(18,733.05)=2.00, p<.001, \eta^{2}=.07$. An examination of the univariate effects revealed no group difference for social networking, $F(3,264)=.89, p>.05$, $\eta^{2}=.01$; however, there were significant differences for all other types of media examined. Nonwithdrawn participants 
Table 1

Estimated Marginal Means and Standard Errors for Hourly Weekly Media Use by Subtype of Social Withdrawal

\begin{tabular}{|c|c|c|c|c|c|c|c|c|c|c|c|c|}
\hline \multirow[b]{3}{*}{ Subtype of social withdrawal } & \multicolumn{12}{|c|}{ Media use } \\
\hline & \multicolumn{2}{|c|}{ E-mail } & \multicolumn{2}{|c|}{$\begin{array}{c}\text { Social } \\
\text { networking }\end{array}$} & \multicolumn{2}{|c|}{ Video games } & \multicolumn{2}{|c|}{$\begin{array}{c}\text { Violent } \\
\text { video games }\end{array}$} & \multicolumn{2}{|c|}{ Gamble } & \multicolumn{2}{|c|}{ Pornography } \\
\hline & $M$ & $S E$ & $M$ & $S E$ & $M$ & $S E$ & $M$ & $S E$ & $M$ & $S E$ & $M$ & $S E$ \\
\hline Avoidant & 10.44 & 2.42 & 14.56 & 2.98 & 11.03 & 1.75 & 8.81 & 1.52 & 3.63 & .60 & 5.84 & 1.10 \\
\hline Shy & 8.68 & 1.81 & 14.56 & 2.24 & 5.11 & 1.31 & 2.09 & 1.14 & .16 & .45 & .77 & .83 \\
\hline Unsocial & 13.14 & 2.54 & 17.97 & 3.13 & 4.52 & 1.84 & 2.31 & 1.60 & .03 & .63 & .65 & 1.16 \\
\hline Nonshy & 4.65 & 1.12 & 10.79 & 1.38 & 3.96 & .81 & 2.91 & .70 & .25 & .28 & .99 & .51 \\
\hline
\end{tabular}

reported significantly fewer hours of e-mail than all three withdrawn subtypes, $F(3,264)=2.82, p>.05, \eta^{2}=.03$. Additionally, the avoidant group played substantially more video games, $F(3,264)=5.32, p<.001, \eta^{2}=.06$, and violent video games, $F(3,264)=5.81, p<.001, \eta^{2}=.06$, gambled (including online), $F(3,264)=9.90, p<.001, \eta^{2}=.10$, and viewed more pornography, $F(3,264)=6.71, p<.001, \eta^{2}=$ .07 , than shy, unsociable, or nonwithdrawn participants. For these latter types of media, there were no significant differences between nonwithdrawn, shy, and unsociable participants.

\section{Bivariate Correlations}

Hours spent engaging in social networking and e-mailing were averaged to form a connective media use variable and video game use, violent video game use, gambling, pornography were averaged to create an overall problematic media use variable. Additionally, all subtypes of withdrawal were treated as continuous variables in the following analyses. Bivariate correlations were computed for connective and problematic media use, social withdrawal (three subtypes), externalizing behavior and depression. For parsimony, we will not report all of the significant correlations (see Table 2 for all results) but several of note include (a) the strong correlations between each respective form of withdrawal at Time 1 and Time 2 suggesting a fair amount of stability in social withdrawal (Tabachnick \& Fidell, 2012), (b) the links between problematic media use and externalizing problems both concurrently and longitudinally, and (c) the negative association between avoidant behavior at Time 1 and connective forms of media at both points in time.

\section{Measurement Model}

In prelude to the structural models tested below, a measurement model was first examined using structural equation modeling via the AMOS Version 23. There were two constructs (shown in Table 3): connective media (two items) and problematic media (four items). Goodness of fit indices suggested that the model adequately represented the data, $\chi^{2}(8)=86.15, p<.01$, comparative fit index $(\mathrm{CFI})=.91$.

\section{Structural Model}

To assess longitudinal associations, a cross-lag structural equation model was estimated using AMOS with all three types of social withdrawal predicting future withdrawal, externalizing behavior, and depression, as mediated by connective and problematic media (see Figure 1). The model fit the data well, $\chi^{2}(51)=126.02$, $p<.001$; CFI $=.96$; root mean square error of approximation $($ RMSEA $)=.06$. Results revealed that avoidance at Time 1 was

Table 2

Bivariate Correlations for Connective and Problematic Media Use, Subtypes of Social Withdrawal, Externalizing Behaviors, and Depression

\begin{tabular}{|c|c|c|c|c|c|c|c|c|c|c|c|c|c|c|}
\hline Variables & 1 & 2 & 3 & 4 & 5 & 6 & 7 & 8 & 9 & 10 & 11 & 12 & 13 & 14 \\
\hline 1. Connective media $\mathrm{T} 1$ & - & & & & & & & & & & & & & \\
\hline 2. Problematic media T1 & $.24^{* * * *}$ & - & & & & & & & & & & & & \\
\hline 3. Shy T1 & .09 & .02 & - & & & & & & & & & & & \\
\hline 4. Unsociable $\mathrm{T} 1$ & .03 & .03 & $.31^{* * * *}$ & - & & & & & & & & & & \\
\hline 5. Avoidant T1 & $-.11^{*}$ & $.14^{* *}$ & $.27^{* * * *}$ & $.41^{\text {**** }}$ & - & & & & & & & & & \\
\hline 6. Externalizing behaviors $\mathrm{T} 1$ & $.12 *$ & $.34^{* * * *}$ & -.03 & -.01 & .10 & - & & & & & & & & \\
\hline 7. Depression T1 & $.11^{*}$ & .02 & $.29^{* * *}$ & $.14^{*}$ & $.16^{* *}$ & .10 & - & & & & & & & \\
\hline 8. Connective media $\mathrm{T} 2$ & $.23^{* * * *}$ & -.03 & -.02 & -.04 & $-.15^{*}$ & .08 & .01 & - & & & & & & \\
\hline 9. Problematic media T2 & .01 & $.46^{* * * *}$ & .06 & .01 & -.02 & $.17^{*}$ & .04 & .12 & - & & & & & \\
\hline 10. Shy T2 & .06 & .07 & $.69^{* * * *}$ & $.23^{* * * *}$ & $.30^{* * * *}$ & .02 & $.25^{\text {**** }}$ & -.04 & .12 & - & & & & \\
\hline 11. Unsociable $\mathrm{T} 2$ & .06 & .03 & .10 & $.52^{* * * *}$ & $.40^{* * * *}$ & -.05 & -.01 & -.03 & -.03 & $.20^{* * *}$ & - & & & \\
\hline 12. Avoidant T2 & -.01 & .04 & $.30^{* * * * *}$ & $.49^{\text {******}}$ & $.55^{* * * *}$ & -.04 & .14 & -.13 & .03 & $.36^{* * * *}$ & $.62^{* * * * *}$ & - & & \\
\hline 13. Externalizing behaviors $\mathrm{T} 2$ & -.04 & $.27^{* * * *}$ & -.05 & -.07 & -.05 & $.64^{* * * *}$ & $.16^{*}$ & .04 & $.19^{* *}$ & -.06 & -.08 & -.04 & - & \\
\hline 14. Depression T2 & $.17^{*}$ & .12 & $.21^{* *}$ & .03 & -.01 & .02 & $.50^{\text {**** }}$ & .08 & $.21^{* * *}$ & $.29^{* * *}$ & -.06 & .12 & .10 & - \\
\hline
\end{tabular}

Note. $\quad \mathrm{T} 1=$ Time $1 ; \mathrm{T} 2=$ Time 2.

${ }^{*} p<.05 . \quad{ }^{* * *} p<.01 .^{* * *} p<.001$. 
Table 3

Standardized Factor Loadings for the Measurement Model of Connective and Problematic Media

\begin{tabular}{clc}
\hline \multicolumn{1}{c}{ Factor } & \multicolumn{1}{c}{ Items/Scale } & Loadings \\
\hline Connective Media & Social networking & .98 \\
& E-mail & .67 \\
Problematic Media & Video games & .92 \\
& Violent video games & .92 \\
& Gambling & .55 \\
& Pornography & .45 \\
\hline
\end{tabular}

positively associated with problematic media use $(\beta=.16, p<$ $.01)$, which in turn was related with externalizing behaviors $(\beta=$ $.16, p<.01)$ and depression $(\beta=.19, p<.05)$ at Time 2 . Indirect effects were assessed using the INDIRECT feature in Mplus. Analyses revealed that problematic media use was a significant mediator of avoidance at Time 1 and externalizing behavior at Time $2(p<.01)$, but not depression at Time 2. $(p>.05)$ Interestingly, though shyness and unsociable behavior were not associated with problematic media use at Time 1 , such media use predicted these subtypes of withdrawal at Time 2 (shy: $\beta=.14$, $p<.05$; unsocial: $\beta=.23, p<.01$ ).

Conversely, avoidance was negatively associated with connective media $(\beta=-.15, p<.05)$. Connective media was also negatively associated with externalizing behavior $(\beta=-.08 p=$
.058 ) at Time 2. However, indirect effects revealed that connective media was not a significant mediator of avoidance at Time 1 and externalizing behaviors $(p>.05)$. Additionally, each type of social withdrawal at Time 1 predicted the same subtype of withdrawal at Time 2 (shyness: $\beta=.66, p<.001$; unsociable: $\beta=.42, p<$ .001 ; avoidance: $\beta=.49, p<.001)$. Finally, both externalizing behavior $(\beta=.80, p<.001)$ and depression $(\beta=.49, p<.001)$ were highly stable over time.

In terms of other variables, externalizing behavior was positively associated with both connective $(\beta=.16, p<.05)$ and problematic media $(\beta=.43, p<.05)$. These types of media predicted various subtypes of withdrawal, externalizing behavior and depression, as outlined earlier. Indirect effects were examined for all potential mediating effects of either type of media on the relationship between externalizing behavior at Time 1 and any outcome or withdrawal subtype at Time 2, with no significant mediators being found ( $p>.05$ for all indirect effects).

\section{Discussion}

The purpose of this study was to conduct a short-term longitudinal study examining the mediating role of media use in the stability of subtypes of social withdrawal and their links with internalizing problems and externalizing behaviors during emerging adulthood. The results of the study provide some of the first evidence of the stability of social withdrawal in emerging adult-

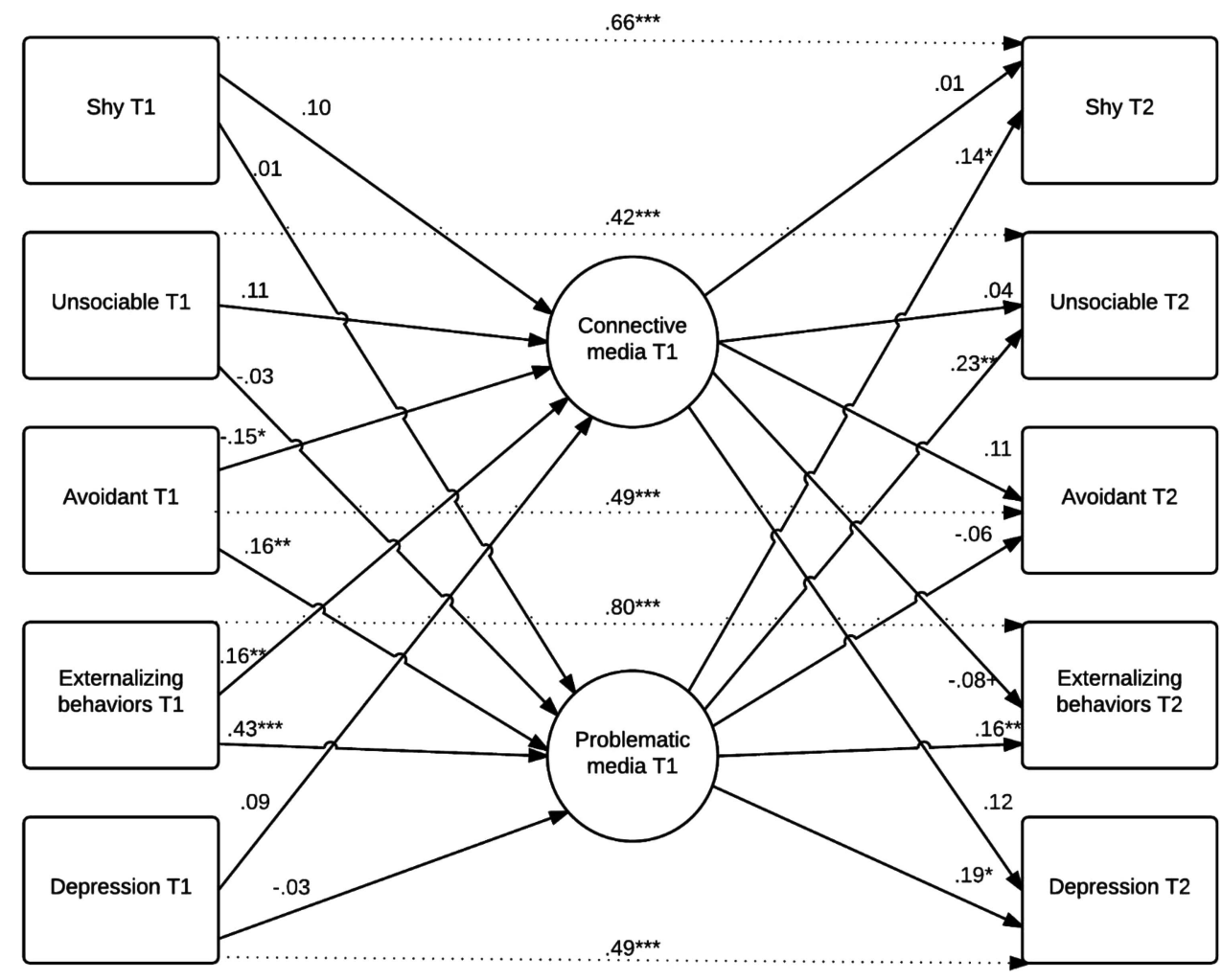

Figure 1. Social withdrawal and problematic behavior as mediated by problematic media use. Endogenous error terms, intercorrelations, and paths between withdrawal types and externalizing behavior and depression at both time points are not shown in the figure for parsimony. ${ }^{+} p<.10 .^{*} p<.05 .{ }^{* * *} p<.01{ }^{* * *} p<.001$. 
hood and the harmful role that problematic media might play in the lives of socially withdrawn emerging adults.

We began by employing a person-centered approach to examine the different patterns of media use in individuals who score high on shy, unsociable, and avoidant behaviors, respectively. Results revealed differences for every type of media use except for social networking. Two findings are particularly noteworthy. First, all withdrawn individuals, regardless of subtype, used e-mail more frequently than their nonwithdrawn peers. Second, the avoidant group played substantially more video games and violent video games, gambled (including online), and viewed more pornography, than shy, unsociable, or nonshy participants (who did not differ from one another). This first set of analyses already began to paint a picture of avoidant behaviors being a possible red flag for risk. So, based on this first set of results, we formed variables reflecting two types of media use (i.e., connective and problematic media use) to further examine the potentially positive or negative roles that media might play in the lives of withdrawn young people. By treating subtypes of withdrawal as continuous variables, analyses revealed that avoidant behavior was positively correlated with problematic media use, and negatively related to connective media use. Again, these analyses point to a problematic relationship between avoidance and media use. However, these links were based only on cross-sectional relations at Time 1.

Hence, in the final set of analyses, we addressed the research question regarding the role of media in the stability of each subtype of withdrawal over time, and the mediating role of media in the link between forms of social withdrawal and internalizing (depression) problems and externalizing behaviors (e.g., use of illegal drugs, shoplifting or vandalizing, smoking cigarettes) over time. Results revealed a fair amount of stability of withdrawn subtypes across time. Of further significance, findings showed the role that connective and, especially, problematic media use plays in the relations between withdrawn behaviors and internalizing and externalizing problems over time especially for avoidant behavior. Specifically, results showed that problematic media use was a significant mediator of avoidance at Time 1 and externalizing behaviors at Time 2. Also, results showed that although shyness and unsociable behavior were not associated with problematic media use at Time 1, such media use predicted these subtypes of withdrawal at Time 2 . Taken together, results of this study make several important contributions to our understanding of social withdrawal and problematic media use in emerging adulthood.

First, the study provides some of the first evidence regarding the stability of various forms of withdrawal in emerging adulthood. Although the study only examined the stability of withdrawal across one year, it is nonetheless important to see the moderate levels of stability of each form of withdrawal. This may give some reason to be concerned about certain withdrawn individuals. Specifically, in work that has used the global term "shy" it has been found that nonsocial individuals struggle in a number of different areas including academically (Hojat, Vogel, Zeleznik, \& Borenstein, 1988), in relationships (Barry, Nelson, \& Christofferson, 2013; Nelson et al., 2008), in identity development (e.g., Barry et al., 2013; Hamer \& Bruch, 1997), and with internalizing problems (Hotard, McFatter, McWhirter, \& Stegall, 1989; Mounts, Valentiner, Anderson, \& Boswell, 2006; Nelson et al., 2008). When studying subtypes of withdrawal (rather than global definitions of shyness), it has been found that both shy and avoidant individuals experience poorer relationships and problems of an internalizing nature (e.g., low self-worth, depression, suicidal ideations; Nelson, 2013). Taken together, the findings may serve as a warning about the mounting problems that might accrue the longer emerging adults engage in shy and avoidant behaviors. Indeed, additional work is needed to better understand the longitudinal outcomes of being withdrawn in the third decade of life. Furthermore, work is needed to examine factors related to either increases or decreases in withdrawn behaviors. In the current study, there was certainly variability in the stability of each form of withdrawal and it would be important to understand factors that lead to fluctuation in the amount of withdrawn behaviors in which young people engage.

In the current study, it was hypothesized that media might be just one such factor that might play a role in the stability of withdrawn behaviors over time. Interestingly, media use did not mediate the stability of any of the forms of withdrawal over time but higher levels of problematic media use at Time 1 led to increases in shy and unsociable behaviors at Time 2 . There are a number of existing studies that have found a link between withdrawn behaviors (again, usually employing a global definition of shyness) and video game use (e.g., Holtz \& Appel, 2011; Huang \& Leung, 2009) but most of this work has been with younger children and adolescents and has been cross-sectional in design. Thus, the results of the current study provide some of the first evidence in the third decade of life that it is not just the fact that nonsocial individuals turn to solitary activities such as video games but at the same time the use of problematic media can lead individuals to become more withdrawn. By examining multiple motivations for withdrawing from social interactions, we found that individuals who have low approach and high avoid motivations (i.e., avoidance) tend to withdraw into solitary use of media (although this link existed at Time 1 and therefore is not a causal finding), but that higher usage of problematic media can actually increase shy and unsociable behaviors over time. These findings are concerning in that they raise the possibility that problematic media use can lead to increases in behaviors that have been linked to numerous indices of maladjustment in emerging adulthood.

Results of the current study also suggest that problematic media not only leads to increases in shy and unsociable behaviors, but also to higher levels of externalizing behaviors. This appears to especially be the case for avoidant behavior as problematic media mediated the association between avoidance and externalizing behaviors with higher levels of avoidance and use of problematic media at Time 1 predicting an increase in externalizing behaviors a year later. Existing work has already shown a link between avoidant behaviors and numerous indices of internalizing problems (e.g., lower self-worth, depression, self-harm, suicidal ideations; Nelson, 2013) so it is disconcerting to discover that high levels of avoidance and problematic media use can work together to also predict problems of an externalizing nature. The findings point to the need for future work to explore the mechanisms through which avoidant individuals who turn to more and more use of problematic media might then, in turn, engage in more externalizing behaviors over time. Indeed, it appears that this type of future work is sorely needed as the growing evidence is beginning to make it very clear that avoidance is a significant risk factor for maladjustment in emerging adulthood.

In sum, the results of this study underscore the need to differentiate between multiple forms of withdrawal in emerging adult- 
hood, and the ways in which subtypes of withdrawal are linked to various forms of media, which, in turn, is related to an increase in withdrawn behaviors and, in the case of avoidance, an increase in externalizing behaviors in emerging adulthood. Past work employing broad, global definitions of shyness would paint a picture of nonsocial individuals that supports the stereotypes of reclusive individuals who spend the majority of their day engaged in solitary forms of media use such as video games. Results of this study, however, counter that stereotype for shy and unsociable individuals as they engaged in no more online gambling, pornography, video game, or violent video game use than their nonwithdrawn peers. They did e-mail more than more sociable emerging adults but this may reflect attempts, at least on the part of shy individuals, to balance their fear of social interaction (i.e., avoidance motivation) with their desire for social interaction (i.e., approach motivation) by connecting with other people electronically (e.g., e-mail). Overall, though, shy and unsociable individuals do not appear to use problematic media to any extent or in any way that would set them apart from more sociable peers or place them at risk for negative outcomes.

Avoidant individuals, on the other hand, appear to fit more of the stereotypical image of individuals who in their attempt to avoid social settings engage in solitary activities that include large amounts of media including violent video games, online gambling, and sexual media. There may be reason for concern for these individuals in the third decade of life because higher levels of problematic media use appear to be in turn linked to higher levels of externalizing behaviors. Hence, results would suggest that not only might avoidant behaviors place emerging adults at risk for internalizing problems (Nelson, 2013) but also for externalizing problems.

\section{Limitations and Conclusions}

Although the study makes numerous contributions to our understanding of withdrawn behaviors in emerging adulthood, it is not without its limitations. First, participants include only college students and, therefore, the findings may not be generalizable beyond that population of young people. Future work needs to include participants who are not attending a 4-year college or university. It may be that findings for college students in regard to these withdrawn behaviors would only be stronger as nonstudents might have more time to engage in media use. Conversely, they may be working more and therefore have less time to spend on media. Regardless, there are ample reasons to suspect that the relations between withdrawn behaviors, media use, and externalizing behaviors might be different for nonstudents during the third decade of life. Second, all of the variables were assessed via self-report which may result in spurious or inflated correlations due to shared method variance. Third, most of the items that tapped avoidance were sociability items that were then reverse scored. It might be argued that they do not directly assess a high-avoidance and low-approach motivation. However, this scale has been employed in previous work and found to be a reliable and useful indicator of a unique form of withdrawal. Fourth, some caution is warranted in how these findings are interpreted given the small to moderate levels of relations among many of the variables. Fifth, there may be both regional (data collected from only two sites in the United States) and cultural factors that affect both the "meaning" of the various forms of social withdrawal and how they are linked to indices of adjustment and maladjustment. Future work within the United States should include greater geographical and ethnic diversity to enhance confidence in the generalizability of the findings and future work outside of the United States should explore the role of culture in the links of social withdrawal and indices of adjustment and maladjustment. Finally, in the optimal mediational design, all three types of variables should be measured at a different point in time (i.e., three time points) so that there is time for the mediating process to unfold. The design employed in our study has been referred to as a half-longitudinal design (Maxwell \& Cole, 2007). Future work should consider employing a full longitudinal design.

Despite the limitations, this study makes several important contributions to understanding social withdrawal and its relationship with media use. First, it provides some of the first evidence of the stability of social withdrawal in emerging adults. Furthermore, the results indicate that all withdrawn participants (avoidant, unsociable and shy) e-mail more than their nonshy peers. Next, results suggest that there may be reason to be concerned about the avoidant-withdrawn group, as these individuals appear to participate in more problematic media use in comparison to other withdrawn (unsociable and shy) and nonwithdrawn emerging adults. Finally, findings from this study point to the role that problematic media use may have in mediating the link between avoidance and externalizing problems in emerging adulthood. Taken together, the results underscore the need to differentiate between multiple forms of withdrawal in emerging adulthood, and to examine the ways in which these different subtypes of withdrawal are linked to various forms of media, which, in turn, is related to an increase in withdrawn behaviors and, in the case of avoidance, and increase in externalizing behaviors during the third decade of life.

\section{References}

Anderson, C. A., Gentile, D. A., \& Buckley, K. A. (2007). Violent video game effects on children and adolescents: Theory, research, and public policy. New York, NY: Oxford University Press. http://dx.doi.org/10 .1093/acprof:oso/9780195309836.001.0001

Anderson, C. A., Shibuya, A., Ihori, N., Swing, E. L., Bushman, B. J., Sakamoto, A., ... Saleem, M. (2010). Violent video game effects on aggression, empathy, and prosocial behavior in eastern and western countries: A meta-analytic review. Psychological Bulletin, 136, 151173. http://dx.doi.org/10.1037/a0018251

Aquilino, W. S. (2006). Family relationships and support systems in emerging adulthood. In J. J. Arnett \& J. L. Tanner (Eds.), Emerging adults in America: Coming of age in the 21st century (pp. 193-217). Washington, DC: American Psychological Association. http://dx.doi .org/10.1037/11381-008

Arnett, J. J. (2000). Emerging adulthood. A theory of development from the late teens through the twenties. American Psychologist, 55, 469480. http://dx.doi.org/10.1037/0003-066X.55.5.469

Asendorpf, J. B. (1990). Beyond social withdrawal: Shyness, unsociability, and peer avoidance. Human Development, 33, 250-259. http://dx.doi .org/10.1159/000276522

Baker, L. R., \& Oswald, D. L. (2010). Shyness and online social networking services. Journal of Social and Personal Relationships, 27, 873889. http://dx.doi.org/10.1177/0265407510375261

Barry, C. M., Nelson, L. J., \& Christofferson, J. (2013). Asocial and afraid: An examination of shyness and anxiety in emerging adulthood. Journal of Family Studies, 19, 2-18. http://dx.doi.org/10.5172/jfs.2012.1979 
Birnie, S. A., \& Horvath, P. (2002). Psychological predictors of internet social communication. Journal of Computer-Mediated Communication, 7.

Bowker, J. C., Nelson, L. J., Markovic, A. K., \& Luster, S. S. (2014). Social withdrawal in adolescence and emerging adulthood. In R. J. Coplan \& J. C. Bowker (Eds.), A handbook of solitude: Psychological perspectives on social isolation, social withdrawal, and being alone (pp. 167-183). New York, NY: Wiley-Blackwell.

Caspi, A., Begg, D., Dickson, N., Harrington, H., Langley, J., Moffitt, T. E., \& Silva, P. A. (1997). Personality differences predict health-risk behaviors in young adulthood: Evidence from a longitudinal study. Journal of Personality and Social Psychology, 73, 1052-1063. http://dx .doi.org/10.1037/0022-3514.73.5.1052

Chak, K., \& Leung, L. (2004). Shyness and locus of control as predictors of internet addiction and internet use. Cyberpsychology \& Behavior, 7, 559-570. http://dx.doi.org/10.1089/cpb.2004.7.559

Chan, M. (2011). Shyness, sociability, and the role of media synchronicity in the use of computer-mediated communication for interpersonal communication. Asian Journal of Social Psychology, 14, 84-90.

Coplan, R. J., Prakash, K., O’Neil, K., \& Armer, M. (2004). Do you "want" to play? Distinguishing between conflicted shyness and social disinterest in early childhood. Developmental Psychology, 40, 244-258. http://dx .doi.org/10.1037/0012-1649.40.2.244

Coplan, R. J., Rose-Krasnor, L., Weeks, M., Kingsbury, A., Kingsbury, M., \& Bullock, A. (2013). Alone is a crowd: Social motivations, social withdrawal, and socioemotional functioning in later childhood. Developmental Psychology, 49, 861-875. http://dx.doi.org/10.1037/a0028861

Coplan, R. J., \& Rubin, K. H. (2010). Social withdrawal and shyness in childhood: History, theories, definitions, and assessments. In R. J. Coplan \& K. H. Rubin (Eds.), The development of shyness and social withdrawal (pp. 3-22). New York, NY: Guilford Press.

Coplan, R. J., \& Weeks, M. (2010). Unsociability in middle childhood: Conceptualization, assessment, and associations with socio-emotional functioning. Merrill-Palmer Quarterly, 56, 105-130.

Fraser, A. M., Padilla-Walker, L. M., Coyne, S. M., Nelson, L. J., \& Stockdale, L. A. (2012). Associations between violent video gaming, empathic concern, and prosocial behavior toward strangers, friends, and family members. Journal of Youth and Adolescence, 41, 636-649. http://dx.doi.org/10.1007/s10964-012-9742-2

Gentile, D. A., Anderson, C. A., Yukawa, S., Ihori, N., Saleem, M., Ming, L. K., ... Sakamoto, A. (2009). The effects of prosocial video games on prosocial behaviors: International evidence from correlational, longitudinal, and experimental studies. Personality and Social Psychology Bulletin, 35, 752-763. http://dx.doi.org/10.1177/0146167209333045

Gentile, D. A., Coyne, S. M., \& Bricolo, F. (2013). Pathological technology addictions: What is scientifically known and what remains to be learned. In K. Dill (Ed.), The oxford handbook of media psychology (pp. 382-402). New York, NY: Oxford University Press.

Halley Grigsby, T. J., Forster, M., Soto, D. W., Baezconde-Garbanati, L., \& Unger, J. B. (2014). Problematic substance use among Hispanic adolescents and young adults: Implications for prevention efforts. Substance Use \& Misuse, 49, 1025-1038.

Hamer, R. J., \& Bruch, M. A. (1997). Personality factors and inhibited career development: Testing the unique contribution of shyness. Journal of Vocational Behavior, 50, 382-400. http://dx.doi.org/10.1006/jvbe .1996 .1542

Henderson, L., \& Zimbardo, P. (1998). Encyclopedia of mental health. San Diego, CA: Academic Press.

Hojat, M., Vogel, W. H., Zeleznik, C., \& Borenstein, B. D. (1988). Effects of academic and psychosocial predictors of performance in medical school on coefficients of determination. Psychological Reports, 63, 383-394. http://dx.doi.org/10.2466/pr0.1988.63.2.383
Holtz, P., \& Appel, M. (2011). Internet use and video gaming predict problem behavior in early adolescence. Journal of Adolescence, 34, 49-58. http://dx.doi.org/10.1016/j.adolescence.2010.02.004

Hotard, S. R., McFatter, R. M., McWhirter, R. M., \& Stegall, M. E. (1989). Interactive effects of extraversion, neuroticism, and social relationships on subjective well-being. Journal of Personality and Social Psychology, 57, 321-331. http://dx.doi.org/10.1037/0022-3514.57.2.321

Huang, H., \& Leung, L. (2009). Instant messaging addiction among teenagers in China: Shyness, alienation, and academic performance decrement. Cyberpsychology \& Behavior, 12, 675-679. http://dx.doi.org/10 $.1089 / \mathrm{cpb} .2009 .0060$

Kaiser Family Foundation. (2010). Key facts: Children and video games. Retrieved from http://www.kff.org/entmedia/3271-index.cfm

Kraut, R., Kiesler, S., Boneva, B., Cummings, J., Helgeson, V., \& Crawford, A. (2002). Internet paradox revisited. Journal of Social Issues, 58, 49-74. http://dx.doi.org/10.1111/1540-4560.00248

Linz, D. G., Donnerstein, E., \& Penrod, S. (1988). Effects of long-term exposure to violent and sexually degrading depictions of women. Journal of Personality and Social Psychology, 55, 758-768. http://dx.doi org/10.1037/0022-3514.55.5.758

Maxwell, S. E., \& Cole, D. A. (2007). Bias in cross-sectional analyses of longitudinal mediation. Psychological Methods, 12, 23-44. http://dx.doi .org/10.1037/1082-989X.12.1.23

Mounts, N., Valentiner, D., Anderson, K., \& Boswell, M. (2006). Shyness, sociability, and parental support for the college transition: Relation to adolescents' adjustment. Journal of Youth and Adolescence, 35, 68-77. http://dx.doi.org/10.1007/s10964-005-9002-9

Nelson, L. J. (2013). Going it alone: Comparing subtypes of withdrawal on indices of adjustment and maladjustment in emerging adulthood. Social Development, 22, 522-538. http://dx.doi.org/10.1111/j.1467-9507.2012 .00671.x

Nelson, L. J., Padilla-Walker, L. M., Badger, S., Barry, C. M., Carroll, J. S., \& Madsen, S. D. (2008). Associations between shyness and internalizing behaviors, externalizing behaviors, and relationships during emerging adulthood. Journal of Youth and Adolescence, 37, 605615. http://dx.doi.org/10.1007/s10964-007-9203-5

Padilla-Walker, L. M., Nelson, L. J., Carroll, J. S., \& Jensen, A. C. (2010). More than a just a game: Video game and internet use during emerging adulthood. Journal of Youth and Adolescence, 39, 103-113. http://dx .doi.org/10.1007/s10964-008-9390-8

Radloff, L. S. (1977). The CES-D scale: A Self-Report Depression Scale for research in the general population. Applied Psychological Measurement, 1, 385-401. http://dx.doi.org/10.1177/014662167700100306

Roberts, L. D., Smith, L. M., \& Pollock, C. M. (2000). "U r a lot bolder on the net": Shyness and internet use. In W. R. Crozier (Ed.), Shyness: Development, consolidation and change (pp. 121-138). New York, NY: Routledge.

Rosser, B. R., Noor, S. W., \& Iantaffi, A. (2014). Normal, problematic, and compulsive consumption of sexually explicit media: Clinical findings using the Compulsive Pornography Consumption (CPC) Scale among men who have sex with men. Sexual Addiction \& Compulsivity, 21, 276-304. http://dx.doi.org/10.1080/10720162.2014.959145

Samenow, C. P. (2013). SASH policy statement (revised): The future of problematic sexual behaviors/sexual addiction. Sexual Addiction \& Compulsivity, 20, 255-258. http://dx.doi.org/10.1080/10720162.2013 .847752

Schmitt, Z. L., \& Livingston, M. G. (2015). Video game addiction and college performance among males: Results from a 1 year longitudinal study. Cyberpsychology, Behavior, and Social Networking, 18, 25-29. http://dx.doi.org/10.1089/cyber.2014.0403

Sheldon, P. (2008). The relationship between unwillingness-tocommunicate and students' Facebook use. Journal of Media Psychology, 20, 67-75. http://dx.doi.org/10.1027/1864-1105.20.2.67 
Southern, S., \& Hilton, K. (2015). Pathological gambling. In R. L. Smith (Ed.), Treatment strategies for substance and process addictions (pp. 149-176). Alexandria, VA: American Counseling Association.

Tabachnick, B. G., \& Fidell, L. S. (2012). Using multivariate statistics. Boston, MA: Pearson.

Wartman, K. L., \& Savage, M. (2008). Parental involvement in higher education: Understanding the relationship among students, parents, and the institution. ASHE Higher Education Report, 33, 1-125.
Yang, S., \& Tung, C. (2007). Comparison of Internet addicts and nonaddicts in Taiwanese high school. Computers in Human Behavior, 23, 79-96. http://dx.doi.org/10.1016/j.chb.2004.03.037

Received September 22, 2014

Revision received January 20, 2016

Accepted March 16, 2016 